VNU Journal of Science: Policy and Management Studies Journal homepage: https://js.vnu.edu.vn/PaM

Review Article

\title{
Covid-19: Some Institutional Issues of the Socialist Oriented Market Economy and Social Development
}

\author{
Nguyen Van Dang*, Luong Quynh Hoa \\ Institute of Sociology and Development, Ho Chi Minh National Academy of Politics, \\ 135 Nguyen Phong Sac, Cau Giay, Hanoi, Vietnam \\ Received 30 August 2020 \\ Revised 13 September 2020; Accepted 16 September 2020
}

\begin{abstract}
Difficulties resulting from the Covid-19 epidemic have revealed more clearly the challenges of economic growth and social development in our country. The current dilemma is also posing an urgent need for sustainable solutions that help both the state and citizens accumulate resources to adapt to unpredictable situations in the future. In order to stop the slowdown and promote economic growth, it is impossible not to consider the core dimensions of the socialistoriented market economy institutions. The paper focuses on analyzing a number of economic institutional challenges, including public ownership, state-owned enterprises, and the legal system. On that basis, the author proposes a number of orientations for institutional innovation towards a more dynamic market economy, a more modern public governance system, in order to achieve social development goals.
\end{abstract}

Keywords: Institutions, Economic Institutions, Socialist Oriented Market Economy, Covid-19.

\footnotetext{
* Corresponding author.

Email:danghcma@gmail.com
}

https://doi.org/10.25073/2588-1116/vnupam.4262 


\title{
Covid-19: Một số vấn đề thể chế kinh tế thị trường định hướng xã hội chủ nghĩa và phát triển xã hội
}

\author{
Nguyễn Văn Đáng*, Lương Quỳnh Hoa \\ Viện Xã hội học và phát triển, Học viện CTQG Hồ Chí Minh, \\ 135 Nguyễn Phong Sắc, Cầu Giấy, Hà Nội, Việt Nam \\ Nhận ngày 30 tháng 08 năm 2020 \\ Chỉnh sửa ngày 13 tháng 9 năm 2020; Chấp nhận đăng ngày 16 tháng 9 năm 2020
}

\begin{abstract}
Tóm tắt: Những khó khăn do hậu quả của đại dịch Covid-19 đã phát lộ rõ hơn các thách thức về tăng trưởng kinh tế và phát triển xã hội ở nước ta. Bối cảnh nan giải hiện nay cũng đang đặt ra nhu cầu bức bách về những giải pháp bền vững nhằm giúp cả nhà nước và người dân có thể tích lũy nguồn lực để có thể thích ứng với những tình huống khó đoán định trong tương lai. Để chặn đà suy giảm và thúc đẩy tăng trưởng kinh tế, không thể không xem xét những chiều cạnh cốt lõi của thể chế kinh tế thị trường định hướng xã hội chủ nghĩa. Bài viết tập trung phân tích một số thách thức thể chế kinh tế, bao gồm chế độ công hữu, doanh nghiệp nhà nước, và hệ thống pháp luật. Trên cơ sở đó, tác giả đề xuất một số định hướng đổi mới thể chế nhằm hướng đến một nền kinh tế thị trường năng động hơn, hệ thống quản trị công hiện đại hơn, để có thể thực hiện được các mục tiêu phát triển xã hội.
\end{abstract}

Tù khóa: Thể chế, thể chế kinh tế, kinh tế thị trường định hướng xã hội chủ nghĩa, Covid-19

\section{Mở đầu}

Xuất hiện tại thành phố Vũ Hán (Trung Quốc) vào tháng $12 / 2019$, theo cổng thông tin

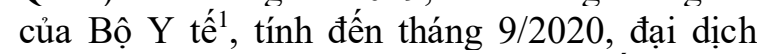
cúm Covid -19 đã lan tới trên 200 quốc gia và vùng lãnh thổ. Cả thế giới đang đứng trước một cuộc khủng hoảng với những tác động tai hại hơn mọi dự báo. Tại Việt Nam, theo GSO (2020), dịch cúm cũng đã gây ra những tác động tiêu cực cho nền kinh tế Việt Nam trong năm tháng đầu năm [1]. Bối cảnh đại dịch đã làm phát lộ rõ hơn nhu cầu bức thiết về phát triển xã hội - đó là xây dựng một xã hội thịnh vượng, phát triển bao trùm, bình đẳng, công bằng, an toàn, và nhân văn. Tuy nhiên, để tiến đến thịnh vượng và thực hiện được phát triển xã hội thì trước hết phải có nguồn lực tích lũy từ sự tăng trưởng kinh tế. Từ đây xuất hiện trở lại những câu hỏi về thể chế kinh tế thị trường (KTTT) định hướng xã hội chủ nghĩa (XHCN) mà Việt Nam đang theo đuổi. Nếu "định hướng XHCN” là một viễn kiến lãnh đạo cần kiên định thì liệu cơ chế và phương tiện can thiệp của nhà nước vào nền kinh tế như đã thực hiện thời gian qua, có phải là lựa chọn phù hợp, xét cả bối cảnh hiện nay và tương lai? Những chiều cạnh nào của thể chế kinh tế Việt Nam hiện tại có thể cản trở tốc độ tăng trưởng kinh tế, qua đó làm chậm việc thực hiện các mục tiêu phát triển xã hội? Bài viết này sẽ phân tích

\footnotetext{
* Tác giả liên hệ.

Địa chi email: danghcma@gmail.com

https://doi.org/10.25073/2588-1116/vnupam.4262

${ }^{1}$ Bộ Y tế (ngày 3/8/2020). Trang tin về dịch bệnh viêm đường hô hấp cấp Covid - 19 https://ncov.moh.gov.vn/
} 
một số vấn đề thể chế kinh tế thị trường định hướng XHCN ở Việt Nam và chỉ ra một số định hướng đổi mới thể chế nhằm thúc đẩy tăng trưởng kinh tế, tạo điều kiện thực hiện các mục tiêu phát triển xã hội.

\section{Thể chế kinh tế thị trường định hướng xã hội chủ nghĩa}

"Thể chế" là khái niệm được sử dụng rộng rãi nhưng, như North (1990: 7) đã chỉ ra: "chúng ta không thể nhìn thấy, cảm nhận, động chạm, thậm chí đo lường các thể chế; chúng là những cấu trúc của tư duy con người" [2]. Hiểu khái quát thì thể chế là tập hợp khá bền vững các quy tắc và thông lệ có tổ chức gắn với các cấu trúc ý nghĩa và nguồn lực, ít biến đổi trước sự thay đồi của cá nhân, đồng thời có khả năng chống chịu tốt trước những kỳ vọng và mong đợi bất thường của cá nhân cũng như sự thay đồi của bối cảnh bên ngoài [3]. Kinh tế học thể chế cổ điển tập trung vào các khung khồ pháp lý của đời sống kinh tế và văn hóa của tổ chức kinh tế. Tuy nhiên, trường phái tân thể chế lại quan tâm hơn đến quy trình và hành động, trong sự phân biệt với tổ chức. Bởi lẽ, theo tiếp cận tân thể chế, thì thể chế quyết định các cơ hội trong xã hội, trong khi các tổ chức được lập ra để tận dụng các cơ hội [2, tr.7]. Chức năng chính yếu của các thể chế là định hình và điều chỉnh hành vi cá nhân, hoạt động của tổ chức, qua đó tạo ra những điều kiện có thể dự báo được cho các hoạt động sống của con người. Như vậy, có thể nhận diện các thể chế kinh tế với ba hình thức tồn tại sau đây:

i) các tổ chức, với chức năng cung cấp những sản phẩm và dịch vụ thiết yếu cho đời sống của con người. Điển hình là các công ty sản xuất và kinh doanh hàng hóa.

ii) các cấu trúc hệ thống định hình hoạt động của một nền kinh tế như hệ thống ngân hàng, hệ thống dự trữ quốc gia, hệ thống thị trường, hệ thống quyền sở hữu tài sản.

iii) các quy tắc quy định hành vi kinh tế của cá nhân cũng như tổ chức, cả thành văn (pháp luật) và bất thành văn (phong tục, tập quán, thông lệ).
Thị trường là nơi diễn ra các quan hệ trao đổi sản phẩm hàng hóa và dịch vụ. Trong xã hội hiện đại, việc trao đổi hàng hóa có thể diễn ra trực tiếp tại một địa điểm nào đó (ví dụ như trung tâm thương mại) hoặc các bên có thể thực hiện mua bán gián tiếp thông qua internet. Phần lớn các quốc gia phát triển trên thế giới hiện nay đang áp dụng mô hình kinh tế thị trường tự do $\mathrm{TBCN}$. Một nền kinh tế thị trường tự do hoàn hảo là khi không có tổ chức nào đứng giữa người mua và người bán $[4,1991: 60)$. Nói cách khác thì đó là nơi mà các cá nhân thực hiện hành vi trao đội một cách hoàn toàn tự nguyên, không chịu bất kỳ sự can thiệp nào [5]. Trong các nền kinh tế thị trường tự do, chế độ sở hữu tư nhân được bảo đảm; tự do kinh tế và cạnh tranh được bảo vệ; lợi ích cá nhân và lợi nhuận được đề cao, chính quyền chỉ giữ vai trò như người trọng tài - chủ thể tạo ra luật chơi và bảo đảm rằng các nguyên tắc pháp lý đó được áp dụng nghiêm minh, công bằng, và bình đẳng giữa các chủ thể của nền kinh tế.

Năm 1986, trước nguy cơ khủng khoảng, Đảng Cộng sản Việt Nam đã dứt khoát thay đồi tư duy, thực hiện công cuộc đổi mới để đưa đất nước trở lại tiến trình phát triển. Công cuộc đổi mới ở Việt Nam về bản chất là tiến trình từng bước mở rộng tự do kinh tế và phát triển thị trường [6, tr.18-21]. Tính chất "thị trường" của nền kinh tế Việt Nam thể hiện ở sự đa dạng các hình thức sở hữu, các thành phần kinh tế, các loại hình doanh nghiệp. Trong khi vai trò chủ đạo thuộc về kinh tế nhà nước, kinh tế tư nhân được khẳng định là một động lực quan trọng của nền kinh tế. Các quyền về sở hữu, tài sản, tự do kinh doanh được bảo vệ; các thành phần kinh tế bình đẳng trước pháp luật và cạnh tranh theo cơ chế thị trường. Việt Nam cũng là nền kinh tế mở và chủ động hội nhập kinh tế toàn cầu. ĐCS Việt Nam cũng xác định bốn đặc điểm chính của "định hướng XHCN" cho nền kinh tế thị trường trong nước, bao gồm: i) nền kinh tế được quản lý bởi nhà nước XHCN do Đảng cộng sản Việt Nam lãnh đạo; ii) mục tiêu phát triển kinh tế là hướng đến dân giàu, nước mạnh, dân chủ, công bằng, văn minh; iii) quan hệ sở hữu, phương thức tổ chức quản lý, quan hệ phân phối được sử dụng 
để ngăn ngừa, giảm thiểu các khuyết tật của thị trường; và iv) phát triển kinh tế gắn với bảo vệ văn hóa, xã hội, môi trường, thực hiện tiến bộ và công bằng xã hội. Sự kiên trì và nhất quán "định hướng XHCN" của nền kinh tế trong nước cho thấy Đảng cộng sản Việt Nam ý thức rõ về những khiếm khuyể do vận dụng các cơ chế thị trường. Cũng bởi thế, định hướng XHCN đề cao sự hợp tác thay vì cạnh tranh, lợi ích tập thể thay vì quá coi trọng lợi ích cá nhân, và phẩm giá con người được coi trọng hơn lợi nhuận. Những định hướng giá trị này cho thấy sự kiên định tinh thần xã hội cốt lõi của chủ nghĩa Marx - Lenin: sự thịnh vượng của cộng đồng không phải là phép cộng giản đơn của những sự thịnh vượng cá nhân. Một cộng động xã hội chỉ được coi là đáng mơ ước nếu chúng ta tạo ra được sự thay đổi tích cực và đồng đều về đời sống cho những tập hợp người đông đảo. Như vậy, đặc điểm nổi bật của thể chế KTTT định hướng XHCN là mức độ tự do kinh tế được kiểm soát; nhà nước có thể can thiệp vào nền kinh tế nhằm bảo đảm các mục tiêu xã hội.

\section{3. Định hướng xã hội chủ nghĩa và phát triển xã hội}

Mặc dù các tư tưởng xã hội đã xuất hiện từ thế kỷ 16 trong tác phẩm Utopia của Thomas More nhưng phải đến thế kỷ 19, CNXH mới định hình là một hệ tư tưởng chính trị [7]. Trước sự hình thành chủ nghĩa tư bản công nghiệp, $\mathrm{CNXH}$ là hệ tư tưởng có thiên hướng bảo vệ lợi ích của những tầng lớp yếu thế như thợ thủ công, nghệ sỹ, và đặc biệt là giai cấp công nhân đang ngày càng gia tăng trong các xã hội tư bản. Ý tưởng căn bản của $\mathrm{CNXH}$ là thay thế hệ thống kinh tế thị trường $\mathrm{TBCN}$, vốn dựa trên chế độ sở hữu tư nhân, bằng một hệ thống kinh tế XHCN, dựa trên chế độ sở hữu toàn dân. $\mathrm{CNXH}$ đề cao giá trị cộng đồng, tình người, bình đẳng xã hội, và phân phối lợi ích vật chất dựa trên nhu cầu của cá nhân chứ không dựa trên lao động hay năng lực. Chính niềm cảm hứng từ các tư tưởng xã hội là một trong những yếu tố dẫn đến sự thành lập Đảng cộng sản Việt Nam vào năm 1930 [8]. Hệ tư tưởng XHCN, thông qua chủ nghĩa Marx -
Lenin, với những triết lý tiến bộ về nhân sinh và xã hội, đã được người dân Việt Nam khi đó vốn đang phải sống cơ cực trong một xã hội thực dân nửa phong kiến, bất bình đẳng nghiêm trọng, nhanh chóng đón nhận. Trải qua hai cuộc chiến tranh, các nhà cách mạng Việt Nam luôn sẵn sàng dấn thân để đất nước có được độc lập, người dân được no ấm, hạnh phúc, tự do, bình đẳng, và hướng về một thế giới đại đồng.

Uu tiên hàng đầu cho tiến trình đổi mới bắt đầu từ năm 1986 là sự điều chỉnh cơ chế và phương thức quản lý kinh tế - xã hội. Sau hơn ba mươi năm thực hiện chuyển đổi sang nền kinh tế thị trường và hội nhập quốc tế, Việt Nam đã được thế giới công nhận là một "câu chuyện thành công" về xóa đói, giảm nghèo, hội nhập, và phát triển [9]. Dù chuyển đổi nền kinh tế sang cơ chế thị trường nhưng Đảng cộng sản Việt Nam vẫn kiên định tinh thần XHCN, nhấn mạnh sự cân bằng giữa mục tiêu tăng trưởng kinh tế và các mục tiêu xã hội. Tuy nhiên, trong những thập kỷ đầu đổi mới, sự hạn chế về các nguồn lực khiến các mục tiêu phát triển xã hội chưa được chú ý đúng mức. Đên đại hội Đảng toàn quốc lần thứ XII (2016), phát triển xã hội đã được coi trọng hơn, trở thành một nội dung trong các văn kiện đại hội. Về tổng thể, các mục tiêu phát triển xã hội mà ĐCS Việt Nam đề ra là sự tiếp tục tư tưởng XHCN, hướng đến một xã hội thịnh vượng, và phát triển đồng đều, hài hòa giữa các cá nhân, giai cấp, và tầng lớp xã hội. Đó là một xã hội đề cao sự hợp tác, các giá trị và lợi ích tập thể, không chấp nhận tình trạng người bóc lột người, và bất bình đăng xã hội nghiêm trọng [6, tr.59-63].

Tuy nhiên, sau hơn ba thập kỷ đổi mới, cho dù nhà nước giữ quyền kiểm soát đối với nền kinh tế, các vấn đề xã hội do sự vận hành của cơ chế thị trường vẫn ngày càng có xu hướng gia tăng [10]. Tình trạng thất nghiệp, phân hóa giàu nghèo, bất bình đẳng xã hội giữa các nhóm, các lĩnh vực kinh tế, và các địa phương là những vấn đề ngày càng trở nên thách thức hơn. Những vấn đề xã hội mới xuất hiện chính là nan đề trong việc xử lý mối quan hệ giữa thể chế KTTT và định hướng XHCN ở Việt Nam, đặt ra những thách thức về lý luận cho Đảng cầm quyền. 


\section{Một số vấn đề của thể chế kinh tế thị trường định hướng xã hội chủ nghĩa}

Chế độ công hữu đối với những tư liệu sản xuất thiết yếu, hệ thống doanh nghiệp nhà nước, và hệ thống luật pháp là những công cụ thể chế chính yếu được nhà nước sử dụng để can thiệp vào nền kinh tế. Bên cạnh những kết quả nhất định, những gì diễn ra sau hơn ba mươi năm đổi mới gợi ra những thách thức thể chế đối với tăng trưởng kinh tế cũng như phát triển xã hội.

Chế độ công hũu tu liệu sản xuất: Tình trạng vi phạm pháp luật để trục lợi từ công sản, điển hình nhất là lĩnh vực đất đai, của cán bộ chính quyền có xu hướng gia tăng, mức độ ngày càng nghiêm trọng hơn đặt ra vân đề về mối liên hệ giữa chế độ công hữu TLSX với tăng trưởng kinh tế và phát triển xã hội. Trong số những cán bộ bị xử lý gần đây, có nhiều lãnh đạo, cựu lãnh đạo các tỉnh, thành, lãnh đạo một số bộ, ngành,... đã bị khởi tố, bắt tạm giam, kỷ luật do liên quan đến sai phạm về đất đai $[11,12]$. Theo đó, có thể thấy chế độ công hữu cùng những yếu kém về quản lý nhà nước đã tạo nhiều kẽ hở cho sự lạm quyền để vụ lợi. Trong bối cảnh cạnh tranh lợi ích, các tài sản công ở nước ta hiện nay như miếng mồi ngon để những chiếc vòi bạch tuộc tham nhũng. Những lỗ hổng trong hệ thống luật pháp và các văn bản dưới luật đã để cho các cá nhân và nhóm lợi ích vị kỷ lợi dụng. Một số cán bộ nhà nước được giao quản lý tài sản công đã tùy tiện đầu tư, sử dụng, chuyển nhượng theo ý mình. Thực tế này giúp chúng ta ý thức rằng những nguồn lực hữu hạn khi được đặt dưới sự quản lý của nhà nước sẽ trở thành miếng mồi hấp dẫn cho các cá nhân và nhóm lợi ích vị kỷ. Khi hệ thống quản lý nhà nước còn nhiều hạn chế thì việc các cá nhân hay nhóm lợi ích trong xã hội tìm cách trục lợi nguồn lực công sẽ là nguy cơ thường xuyên. Nếu tình trạng trục lợi nguồn lực công tiếp tục diễn ra thì thực chất chế độ công hữu đã góp phần gia tăng bất bình đẳng xã hội.

\footnotetext{
Đầu tư online (ngày 21/11/2016).

https://baodautu.vn/infographics-nhung-du-an-nghin-tydap-chieu-d54932.html.
}

Tiến trình đổi mới đất nước cũng làm cho cơ cấu xã hội Việt Nam ngày càng trở nên đa dạng hơn. Sự phát triển nền kinh tế nhiều thành phần đã làm thay đổi cả về số lượng và chất lượng của các nhóm/tầng lớp/giai cấp trong xã hội [13]. Bên cạnh giai cấp nông dân, giai cấp công nhân đang ngày càng tăng về số lượng. Quy mô tầng lớp trí thức cũng ngày càng mở rộng trong khi tầng lớp doanh nhân cũng không ngừng lớn mạnh, có vai trò ngày càng quan trọng trong đời sống kinh tế-xã hội. Đồng thời, giữa các nhóm/tầng lớp/giai cấp xã hội cũng diễn ra sự thay đổi về hình thức và tính chất các mối quan hệ. Với cấu trúc giai tầng xã hội hiện nay, không phải cá nhân nào cũng có thể sở hữu tư liệu sản xuất. Do đó, địa vị xã hội của họ không phụ thuộc vào tư liệu sản xuất. Đây chính là cơ sở để nhận định rằng chế độ công hữu tư liệu sản xuất không nhất thiết tạo ra sự bình đẳng và công bằng xã hội.

Hệ thống doanh nghiệp nhà nuoóc: Hệ thống doanh nghiệp nhà nước là một phương tiện chủ đạo để nhà nước có thể can thiệp nhằm bảo đảm định hướng cho sự phát triển kinh tế. Tuy nhiên, kết quả hoạt động và đóng góp của các doanh nghiệp nhà nước vào tốc độ tăng trưởng kinh tế quốc gia còn rất hạn chế. Trong ba năm (20162018), kinh tế nhà nước chỉ đóng góp vào tăng trưởng GDP loanh quanh ở mức $28 \%$, thậm chí năm 2018 còn giảm xuống $27,6 \%$, bằng khoảng $2 / 3$ so với đóng góp của khu vực kinh tế tư nhân $(42,1 \%)$. Nhiều dự án đầu tư công rơi vào tình trạng "đắp chiếu": theo Bộ Công thương, đến năm 2016 có tới 5 dự án với tổng vốn đầu tư hơn 30.000 tỷ đồng từ ngân sách nhà nước hiện đang trong tình trạng ngừng hoạt động. Đây là những dự án được đầu tư lớn với kỳ vọng tạo ra động lực mới cho phát triển kinh tế quốc gia nhưng kết quả lại là những khoản thua lỗ lớn [14]².

Được ưu ái về cơ chế và nguồn lực nhưng nhiều doanh nghiệp nhà nước lại hoạt động rất kém hiệu quả, thậm chí thua lỗ trầm trọng. Năm 2019, kiểm toán nhà nước đã kiểm toán báo cáo 
tài chính và các hoạt động liên quan đến quản lý, sử dụng vốn nhà nước năm 2018 của 36 tập đoàn, tổng công ty, và công ty nhà nước. Theo đó, có 31/36 doanh nghiệp được kiểm toán sản xuất kinh doanh có lãi; tỷ suất lợi nhuận trên vốn chủ sở hữu, thu nhập bình quân của người lao động tại một số đơn vị đạt tương đối cao. Tuy nhiên, một số đơn vị có hệ số nợ phải trả trên vốn chủ sở hữu cao. Nhiều doanh nghiệp có dấu hiệu mất an toàn tài chính hoặc được đưa vào diện giám sát tài chính. Nhiều công ty con của các tập đoàn, tổng công ty sản xuất kinh doanh không hiệu quả, thua lỗ lớn. Một số khoản đầu tư của các tập đoàn, tổng công ty vào công ty liên kết, đầu tư dài hạn khác bị thua lỗ, mất vốn. Tình trạng này cho thấy, có không ít những doanh nghiệp nhà nước đang là gánh nặng cho nhà nước chứ không phải là trụ đỡ cung cấp nguồn lực cho sự phát triển đất nước, trong đó có phát triển xã hội [15].

Hệ thống pháp lý: Nền kinh tế thị trường định hướng XHCN sẽ không thể phát triển nếu thiếu hệ thống luật pháp chặt chẽ, khuyến khích tự do kinh tế, và bảo vệ cạnh tranh bình đẳng. Tù̀ sau năm 1986, Việt Nam đã nỗ lực xây dựng hệ thống pháp lý nhằm thúc đẩy đầu tư sản xuất và mở rộng tự do kinh doanh. Năm 1985, bộ luật Dân sự với những quy định về quyền sở hữu tài sản, về hợp đồng, về trách nhiệm dân sự,... là đạo luật đầu tiên đặt nền tảng pháp lý chung cho hoạt động kinh doanh. Hai năm sau, Luật đầu tư nước ngoài - đạo luật đầu tiên về kinh doanh được công bố. Tiếp đó, hệ thống pháp luật kinh tế từng bước được hoàn thiện với hàng loạt bộ luật về đầu tư, kinh doanh, quan hệ lao động được ban hành và liên tục hoàn thiện.

Tuy nhiên, theo đánh giá của giới nghiên cứu và cộng đồng doanh nghiệp, hệ thống pháp luật của Việt Nam vẫn chưa thực sự tạo thuận lợi cho tự do kinh tế. Doanh nghiệp vẫn phải đối diện với "rừng" thủ tục hành chính [16]. Chẳng hạn như, Luật Doanh nghiệp 2014 quy định doanh nghiệp được tự do kinh doanh và không phải ghi ngành nghề kinh doanh trên giấy chứng nhận đăng ký doanh nghiệp. Thế nhưng, cơ quan quản lý nhà nước vẫn yêu cầu doanh nghiệp phải làm thủ tục đăng ký như cũ. Việc này gần như không có ý nghĩa gì, kể cả cho việc thống kê, vì doanh nghiệp được tự do khai báo hàng nghìn ngành, nghề, nên khác xa hoạt động kinh doanh thực tế của họ. Trong lĩnh vực pháp luật về lao động, mặc dù Bộ luật Lao động năm 2012 đã xác định có thị trường lao động và sức lao động là hàng hóa, nhưng vẫn còn nhiều quy định ràng buộc quá chặt chẽ, dẫn đến ách tắc lớn trong việc tự do bán sức lao động và quyền tự do tuyển chọn, sử dụng lao động. Việc người lao động chấm dứt hợp đồng lao động cũng như việc doanh nghiệp sa thải lao động rất khó khăn. Doanh nghiệp cũng không được phép cho thuê, cho mượn lao động, dù chỉ là để giải quyết nhu cầu cần thiết tạm thời. Bên cạnh đó là những chính sách ưu đãi về nguồn lực và cơ chế giành cho khối doanh nghiệp nhà nước cũng như khối doanh nghiệp FDI. Trong khi đó, mặc dù đóng góp ngày càng lớn vào tỷ trọng GDP quốc gia, khối doanh nghiệp tư nhân trong nước còn chịu nhiều sự đối xử thiếu công bằng, chưa được hố trợ đúng mức.

\section{5. Định hướng đổi mới thể chế}

Kinh tế thị trường định hướng XHCN nhấn mạnh các mục tiêu phát triển xã hội trong tiến trình phát triển đất nước. Theo đó, tăng trưởng kinh tế luôn phải đặt trong mối quan hệ với phát triển xã hội. Quá trình ứng phó với dịch cúm Covid-19 cho thấy nhà nước sẽ không thể đủ nguồn lực cho các nhu cầu vốn rất khó lường trước của người dân. Bởi thế, nhà nước sẽ luôn cần sự hợp tác từ các chủ thể ngoài nhà nước, nhất là trong những tình huống bất thường. Để xã hội có được sự tăng trưởng kinh tế và các chủ thể ngoài nhà nước tích lũy được nguồn lực thì các vấn đề về quyền sở hữu tài sản, tự do kinh tế, và các quy luật thị trường cần phải được tôn trọng và bảo vệ. Mở rộng tự do kinh tế và thị trường giúp đẩy nhanh tốc độ tăng trưởng kinh tế, giảm bớt căng thẳng hoặc xung đột giữa các nhóm xã hội; hoặc giữa các nhóm xã hội với chính quyền. Bởi sự linh hoạt của thị trường sẽ thúc đầy sự năng động, sáng tạo, sử dụng hiệu quả các nguồn lực. Các quan hệ trao đổi được thực hiện thuận lợi hơn trên cơ sở tự nguyện. Qua đó, sự thịnh vượng của cả xã hội được nâng lên 
nhanh hơn, trở thành nền tảng để thực hiện các mục tiêu phát triển xã hội.

Để hướng tới sự trưởng thành của thể chế kinh tế thị trường và thúc đẩy tăng trưởng kinh tế, pháp luật giữ vai trò đặc biệt quan trọng. Tuy nhiên, để có hệ thống pháp luật khuyến khích sản xuất, kinh doanh thì trước hết phải giải quyết được mối quan hệ giữa chính trị và hành chính. Cụ thể hơn là mối quan hệ giữa Đảng với Nhà nước; giữa chính quyền với doanh nghiệp và người dân. Tất cả các mối quan hệ đó cần được cụ thể hóa và thể chế hóa chặt chẽ hơn nữa để minh định mức độ, phạm vi, và phương thức can thiệp của nhà nước vào nền kinh tế. Xu hướng khu vực và thế giới cho thấy Việt Nam phải đẩy nhanh hơn nữa tiến trình hiện đại hóa thể chế hoạch định và thực thi chính sách. Trong đó, đặc biệt quan trọng là hệ thống hành chính phải vận hành như một cỗ máy thực thi chính sách công tâm, giảm thiểu nguy cơ bị chi phối bởi các quan hệ thân hữu hay lợi ích phe nhóm.

Để đạt được sự cân bằng giữa tăng trưởng kinh tế và phát triển xã hội, hẳn nhiên chúng ta cần xem xét thấu đáo các phương tiện và cách thức mà nhà nước đang sử dụng để can thiệp vào nền kinh tế. Sự can thiệp của nhà nước nếu không dựa trên những căn cứ khoa học, khách quan, tư duy duy lý thì rất dễ trở thành lực cản cho tăng trưởng kinh tế. Khi đó, chúng ta không chỉ khó đạt được các mục tiêu kinh tế mà còn không có đủ nguồn lực để hiện thực hóa các mục tiêu phát triển xã hội. Đây chính là lý do cho sự xem xét một cách khoa học và thấu đáo các vấn đề về chế độ công hữu TLSX, hệ thống doanh nghiệp nhà nước; hệ thống luật pháp, cũng như vai trò của những yếu tố thể chế này đối với tăng trưởng kinh tế và phát triển xã hội.

Tình huống đại dịch khó khăn càng cho thấy rõ hơn nhu cầu bức thiết về một hệ thống quản trị công hiện đại phù hợp với bối cảnh Việt Nam - đó là hệ thống thể chế bảo đảm được vị thế và vai trò lãnh đạo của đảng cầm quyền nhưng đồng thời cũng phải ngăn chặn được nguy cơ lạm quyền, lợi dụng vai trò của nhà nước để thao túng thị trường. Một hệ thống thể chế quản trị hiện đại cũng sẽ khiến các nhóm lợi ích trong xã hội không thể dễ dàng tác động đến quy trình chính sách theo hướng trục lợi không chính đáng. Những cá nhân vị kỷ trong hệ thống công quyền cũng không thể lợi dụng danh nghĩa Đảng và nhà nước để chi phối quy trình chính sách, qua đó làm méo mó các chủ trương, đường lối phát triển đất nước mà Đảng đã đề ra. Chỉ có như vậy, tự do kinh tế mới được mở rộng và bảo vệ, và thể chế kinh tế thị trường mới có thể phát triển. Tăng trưởng kinh tế nhờ thể chế thị trường hiện đại không chỉ giúp nhà nước và cộng đồng có nhiều nguồn lực cho phát triển xã hội, mà còn sẽ củng cố và gia tăng tính chính danh cho quyền lực nhà nước và cả hệ thống chính trị, trong đó có Đảng cộng sản Việt Nam.

\section{Tài liệu tham khảo}

[1] General Statistics Office of Vietnam, Socioeconomic reporrt for the first 5 months in 2020 (in Vietnamese), Hanoi, 2020.

[2] D.C North, Institutions, Institutional Change and Economic Performance, Cambridge University Press, Cambridge, 1990.

[3] J.G. March, Rediscovering Institutions, Free Press, New York, 1989.

[4] W. Lazonick, Business Organization and the Myth of the Market Economy, Cambridge University Press, Cambridge, 1991.

[5] M. Friedman, Capitalism and Freedom, $3^{\text {rd }}$ ed, The University of Chicago Press, Chicago, 2002.

[6] Communist Party of Vietnam, Report on 10 years of implementation of the Platform in 2011, National Political Publishing House, 2020.

[7] A. Heywood, , Politics, Palgrave Macmillan, 2013, p. 53.

[8] VTV.VN, How was the Vietnam Communist Party born? (in Vietnamese, https://vtv.vn/hoi-dap-vedang-cong-san/dang-cong-san-viet-nam-ra-doinhu-the-nao-20200608222820579.htm, 2020 (accessed 25 July, 2020)

[9] World Bank and the Ministry of Planning and Investment of Vietnam, Vietnam 2035: toward prosperity, creativity, equity, and democracy, Research Report, 2016.

[10] H.T. Phuong, Social classification of income and expenditure in Vietnam (in Vietnamese), Hue University Journal of Science, Vol. 126, No. 6B, 2017.

[11] N. Nhu, Part 1: Many officers "left" ... because of the land! (in Vietnamese), People's Public Security 
Newspaper, http://cand.com.vn/Van-de-hom-naythoi-su/Bai-hoc-trong-cong-tac-phong-chongtham-nhung-tai-san-cong-590177/, 2020 (accessed 25 July, 2020).

[12] H. Son, Do land management gaps facilitate corruption? (In Vietnamese), Finance magazine, http://tapchitaichinh.vn/tai-chinh-phap-luat/lohong-quan-ly-dat-dai-co-tiep-tay-cho-thamnhung-322501.html, 2020 (accessed 25 July, 2020)

[13] N.V. Khanh, N.T. Anh, Change of social structure in Vietnam after 30 years of Doi Moi and a number of development management issues in Vietnam (in Vietnamese), http://viennccspt.hcma1.vn/nghiencuu-hoc-thuat/bien-doi-co-cau-xa-hoi-sau-30nam-doi-moi-va-mot-so-van-de-ve-quan-ly-phattrien-o-viet-nam-tac-gia:-gs-.ts-.-nguyen-vankhanh-pgs-.ts-.-nguyen-tuan-anh-a286.html, 2014 (accessed 27 July, 2020).
[14] L. Bang, Revealing many state-owned enterprises with trillion losses and accumulating debts (in Vietnamese), https://vietnamnet.vn/vn/kinhdoanh/dau-tu/phat-lo-nhieu-doanh-nghiep-longan-ty-no-nan-chong-chat-643292.html, 2020 (accessed 27 July, 2020).

[15] V. Chi, Comparison of private sector and state economy: Who is leading? (in Vietnamese), Vietnamfinance, https://vietnamfinance.vn/sosanh-khu-vuc-kinh-te-tu-nhan-va-kinh-te-nhanuoc-ai-dang-la-chu-dao-

20180504224222929.htm, 2019 (accessed 27 July, 2020).

[16] T.T. Duc, Completing laws, promoting investment and business activities (in Vietnamese), https://nhandan.com.vn/thoi-su-phap-luat/hoanthien-phap-luat-thuc-day-hoat-dong-dau-tu-kinhdoanh-606113/, 2016 (accessed 27 July, 2020). 